\section{Dystrophin expression in the mdx mouse restored by stem cell transplantation}

\author{
Emanuela Gussoni ${ }^{\star}$, Yuko Soneoka $\dagger \ddagger$, Corinne D. Strickland ${ }^{\star}$, \\ Elizabeth A. Buzney ${ }^{\star}$, Mohamed K. Khan $\$$, Alan F. Flint ${ }^{\star} \dagger$, \\ Louis M. Kunkel ${ }^{\star} \ddagger$ \& Richard C. Mulligan $\dagger \ddagger$
}

${ }^{\star}$ Division of Genetics, $\dagger$ Howard Hughes Medical Institute and $\S$ Department of Surgical Research, Children's Hospital, Boston, Massachusetts 02115 USA

‡Department of Genetics, Harvard Medical School, Boston, Massachusetts 02115, USA

The development of cell or gene therapies for diseases involving cells that are widely distributed throughout the body has been severely hampered by the inability to achieve the disseminated delivery of cells or genes to the affected tissues or organ ${ }^{1}$. Here we report the results of bone marrow transplantation studies in the $m d x$ mouse, an animal model of Duchenne's muscular dystrophy ${ }^{2}$, which indicate that the intravenous injection of either normal haematopoietic stem cells or a novel population of muscle-derived stem cells into irradiated animals results in the reconstitution of the haematopoietic compartment of the transplanted recipients, the incorporation of donor-derived nuclei into muscle, and the partial restoration of dystrophin expression in the affected muscle. These results suggest that the transplantation of different stem cell populations, using the procedures of bone marrow transplantation, might provide an unanticipated avenue for treating muscular dystrophy as well as other diseases where the systemic delivery of therapeutic cells to sites throughout the body is critical. Our studies also suggest that the inherent developmental potential of stem cells isolated from diverse tissues or organs may be more similar than previously anticipated.

To determine whether transplantation of bone marrow cells carrying a wild-type dystrophin gene could restore dystrophin expression within the myofibres of the $m d x$ mouse, nine female $m d x$ mice were lethally irradiated and subsequently injected via the tail vein with $5 \times 10^{5}$ or $1-5 \times 10^{7}$ bone marrow cells from normal male C57BL/10 mice (Table 1). Five weeks after transplantation, the haematopoietic cells of all transplanted animals were donor-derived (of male origin), as determined by fluorescence in situ hybridization (FISH) analysis for Y-chromosome-specific sequences (data not shown). At 5, 8 and 12 weeks after bone marrow transplantation, the tibialis anterior muscle from each transplanted animal was analysed for dystrophin expression by immunohistochemistry, followed by FISH analysis using a Y-chromosome-specific probe to detect donor-derived (male) cells (Table 1; Fig. 1). Because previous studies of nuclear domains in myofibres had shown that the expression of a protein can extend several micrometres away from the source nucleus ${ }^{3-6}$, around 20 serial sections were analysed to attempt to associate a dystrophin-positive fibre with a donorderived (male) nucleus.

At five weeks after bone marrow transplantation, less than $1 \%$ of the myofibres expressed dystrophin (Table 1), similar to background reversion levels described in other studies ${ }^{7}$. Eight weeks after bone marrow transplantation, however, about $1 \%$ of the muscle fibres expressed dystrophin in their normal sarcolemmal location, with $25-63 \%$ of dystrophin-expressing fibres containing detectable fused donor-derived nuclei (Table 1 ). By 12 weeks after bone marrow transplantation, as many as $10 \%$ of the muscle fibres within an individual mouse expressed dystrophin, with 10-30\% of the dystrophin-positive myofibres containing detectable fused Y-chromosome-positive nuclei (Table 1; Fig. 1a, b).
Although other studies have documented the capacity of bonemarrow-derived cells to give rise to muscle ${ }^{8,9}$, the identity of the cells with that potential had not been determined. To address this issue, we asked whether highly purified haematopoietic stem cells (HSCs) could give rise to dystrophin-positive myofibres after bone marrow transplantation. HSCs were isolated from the bone marrow of normal male C57BL/10 mice by fluorescence-activated cell sorting (FACS) purification of Hoechst 33342-stained (H0342) cells, as described ${ }^{10}$. These HSCs, termed SP cells, are Sca- $1^{+}, \mathrm{c}-\mathrm{Kit}^{+}, \mathrm{CD} 43^{+}$, $\mathrm{CD} 45^{+}$, lineage marker (B220, Mac-1, Gr-1, CD4, CD5, and CD8)low/negative and CD34-negative, and can completely engraft recipients at very low cell numbers $(100-500 \text { cells per mouse })^{10,11}$. We injected 2,000-5,000 bone marrow SP cells of male origin into the tail veins of nine lethally irradiated female $m d x$ mice (Table 1 ). Mice were killed 5, 8 and 12 weeks after stem cell injection and FISH analysis of the bone marrow confirmed that the female host was completely reconstituted with male donor cells (data not shown). The tibialis anterior muscle was examined for dystrophin expression and the presence of male donor cells by the analysis of serial sections, as described above (Table 1). As was the case with recipients engrafted with unfractionated bone marrow cells, less than $1 \%$ of the myofibres expressed dystrophin at 5 weeks (Table 1). At 8 weeks, up to $1 \%$ of the muscle fibres expressed dystrophin, with $20-40 \%$ of dystrophin-expressing fibres containing fused Y-chromosome-positive nuclei (Table 1). At 12 weeks, dystrophin was detected in up to $4 \%$ of the myofibres, with $10-30 \%$ of these containing fused donor nuclei (Table 1; Fig. 1c-f).

Donor-derived nuclei were associated with both individual dystrophin-positive fibres and clusters of dystrophin-positive
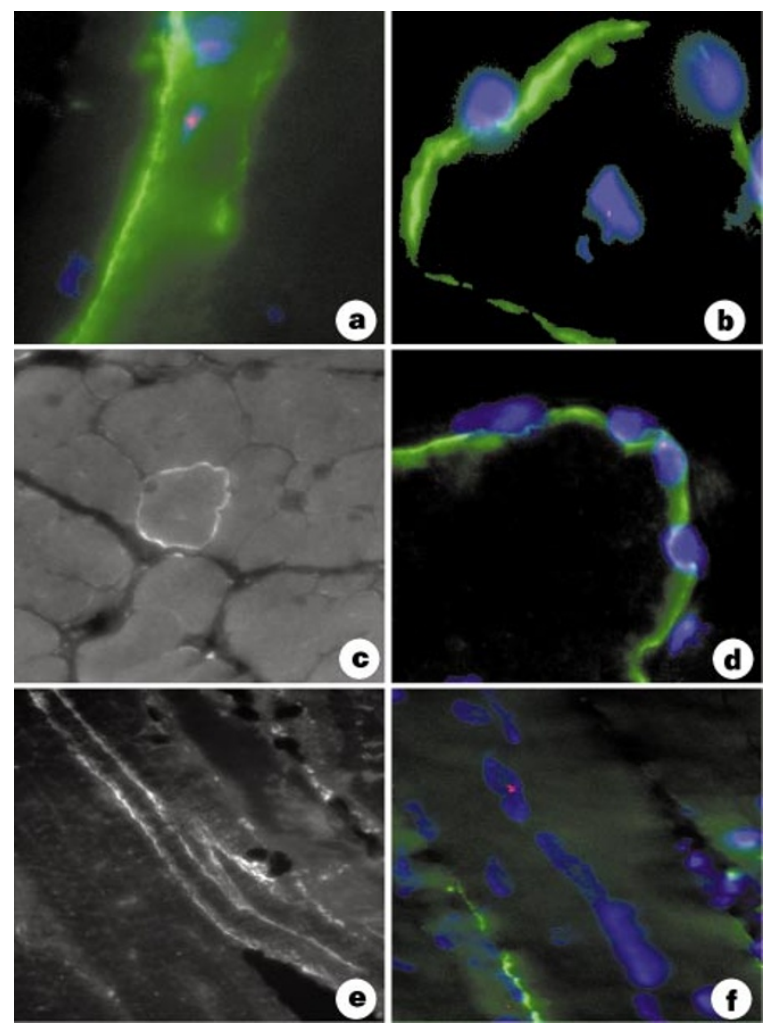

Figure 1 Dystrophin expression and detection of $Y$-chromosome-positive nuclei in the tibialis anterior muscle 12 weeks after whole bone marrow or haematopoietic stem cell transplantation into lethally irradiated female $m d x$ recipients. Donor nuclei (nuclei counterstained with DAPI in blue and $Y$ chromosomes shown as red hybridization signals) were found fused to dystrophin-positive myofibres (in green) at 12 weeks after either whole bone marrow $(\mathbf{a}, \mathbf{b})$ or highly purified haematopoietic stem cell transplantation (cf). In $\mathbf{f}$, the fused donor nucleus was detected further upstream of the dystrophin-positive fibre shown in e. 


\begin{tabular}{|c|c|c|c|c|}
\hline No. of animals & $\begin{array}{l}\text { Weeks after } \\
\text { injection }\end{array}$ & No. cells injected ${ }^{*}$ & $\begin{array}{l}\% \text { Dys }^{+} \text {myofibres } \\
\text { (total) } \dagger\end{array}$ & $\begin{array}{c}\% \mathrm{Y}^{+} \text {nuclei in } \\
\text { myofibresł }\end{array}$ \\
\hline 3 & 5 & $\begin{array}{c}5 \times 10^{5} \text { per animal } \\
(\text { WBM })\end{array}$ & $\begin{array}{c}0.5 ; 0.5 ; 1 \\
(795)\end{array}$ & $0 ; 0 ; 0$ \\
\hline 3 & 8 & $\begin{array}{c}5 \times 10^{5} ; 5 \times 10^{7} ; 5 \times 10^{7} \\
\text { (WBM) }\end{array}$ & $\begin{array}{c}1 ; 1 ; 1 \\
(919)\end{array}$ & $63 ; 36 ; 25$ \\
\hline 3 & 12 & $\begin{array}{c}1 \times 10^{7} ; 5 \times 10^{7} ; 5 \times 10^{7} \\
\text { (WBM) }\end{array}$ & $\begin{array}{c}10 ; 5 ; 1 \\
(552)\end{array}$ & $12 ; 8 ; 33$ \\
\hline 4 & 5 & $\begin{array}{c}\text { 2,000 per animal } \\
\text { (BM-SP) }\end{array}$ & $\begin{array}{c}0.5 ; 0.5 ; 0.6 ; 0.7 \\
(1,016)\end{array}$ & $0 ; 0 ; 0 ; 0$ \\
\hline 2 & 8 & $\begin{array}{l}\text { 2,000 per animal } \\
\text { (BM-SP) }\end{array}$ & $\begin{array}{l}1 ; 0.5 \\
(1,715)\end{array}$ & $39 ; 22$ \\
\hline 3 & 12 & $\begin{array}{c}2,000 ; 5,000 ; 5,000 \\
(\mathrm{BM}-\mathrm{SP})\end{array}$ & $\begin{array}{l}4 ; 1 ; 3 \\
(1,214)\end{array}$ & $12 ; 28 ; 14$ \\
\hline
\end{tabular}

*WBM: whole bone marrow; BM-SP: bone-marrow SP cells.

† Percentage of dystrophin-positive fibres in each animal. (total) represents the average total number of myofibres.

¥; Percentage of dystrophin-positive fibres for which a Y-chromosome-positive nucleus was found in the skeletal muscle of each animal for all sections analysed (on average, one or none per section).

fibres. Among 39 photographed sections, 4-8 $\mathrm{Y}^{+}$nuclei were centrally located, 5-6 nuclei were peripherally located within myofibres and 7-9 nuclei were clearly fused to host myofibres but their location (central or peripheral) was uncertain. However, in some cases where clusters of dystrophin-positive fibres were analysed, no more than a single male nucleus was found. This finding could be due to either preferential fusion of $\mathrm{Y}^{+}$donor cells to clusters of revertant fibres or, alternatively, to an underestimate of the actual proportion of dystrophin-positive fibres associated with donor-derived nuclei. In fact, only a portion of each myofibre was analysed by immunohistochemistry and FISH, and control
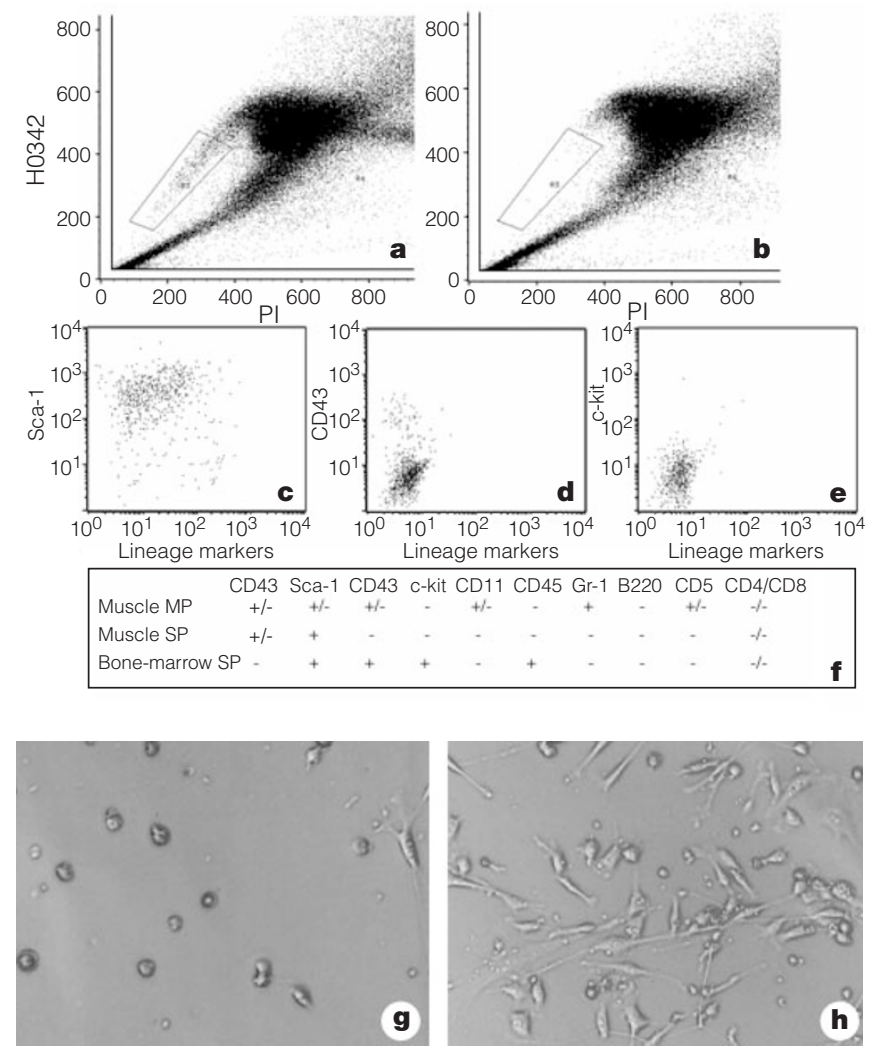

Figure 2 Isolation and characterization of muscle SP cells. A side population (SP) of cells was identified by FACS analysis (a, boxed area). In the presence of verapamil, this population was not visible (b). Over $80 \%$ of muscle SP cells express the antigen Sca- 1 and are negative for lineage markers (c), CD43 (d) and c-Kit (e). The antigens expressed on muscle SP and MP cells compared to bone marrow SP cells are shown in $\mathbf{f} .+/-$, mixture of positive and negative cells; +, cells positive for the marker; - , cells negative for the marker. Muscle SP cells (g) and MP cells (h) in culture appear morphologically different. experiments showed that the FISH analysis does not identify $100 \%$ of male nuclei. In addition, although the percentage of fibres associated with a donor-derived nucleus appeared to decrease at longer times after transplantation of bone marrow cells (Table 1), this may be simply because the domain of dystrophin expression from an individual donor nucleus increasing with time $e^{3-6}$.

As the Hoechst 33342 staining/FACS method for purification of haematopoietic stem cells appears to depend upon a set of physical properties that are common to haematopoietic stem cells from many species, including humans, in a manner independent of antibodies ${ }^{11}$, we next asked whether this method could be used to isolate putative stem cells from skeletal muscle. Mononuclear cells were isolated from 3-5-week-old mouse skeletal muscle ${ }^{12}$, stained with $12.5 \mu \mathrm{g} \mathrm{ml}^{-1}$ of $\mathrm{H} 0342$, and analysed as described ${ }^{10}$. As observed after the staining of bone marrow cells, FACS analysis of muscle cells revealed a side population (SP) displaying low staining with $\mathrm{H} 0342$ and a main population (MP) of cells that were more brightly stained with the dye (Fig. 2a). As was the case for bone marrow SP cells, the muscle SP cell population disappeared upon addition of verapamil (Fig. 2b), a drug that blocks the efflux of
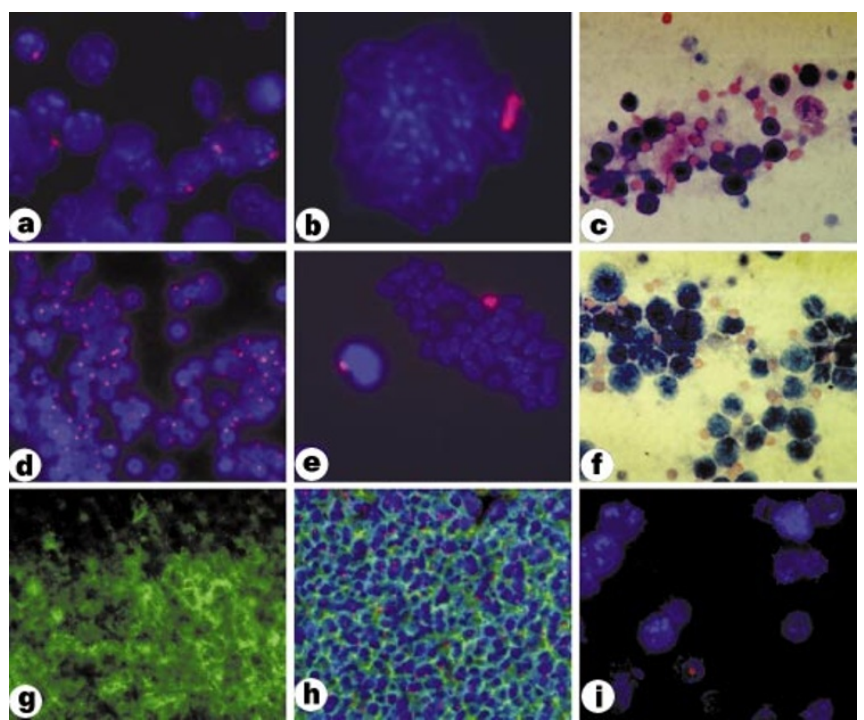

Figure 3 Detection of donor nuclei in the bone marrow and spleen of $m d x$ recipients after injection of muscle SP cells. a-c, Bone marrow, animal 4; d-f, bone marrow, animal 3. Y-chromosomes are detected as red hybridization signals over the nuclei (a, d, $60 \times$ original magnification). Y-chromosome positive metaphases were detected at high magnification (b, e, 100x). Giemsa stain of bone marrow samples shows the presence of several cell types $(\mathbf{c}, \mathbf{f}, 100 \times)$. Expression of CD43 (g) or CD45 (h) antigens in spleen tissue sections from cells of donor origin (h); animal 3. i, Detection of few male nuclei in the bone marrow of animals co-injected with muscle and bone marrow SP cells. 
Table 2 Detection of donor-derived dystrophin-positive muscle fibres after transplantation of muscle SP cells

\begin{tabular}{|c|c|c|c|c|c|}
\hline Animal & $\begin{array}{l}\text { Days after } \\
\text { injection }\end{array}$ & $\begin{array}{l}\text { No. cells } \\
\text { injected }\end{array}$ & $\begin{array}{c}\% \text { Dys }^{+} \text {myofibres } \\
\text { (total) }^{\star}\end{array}$ & $\begin{array}{c}\% \mathrm{Y}^{+} \text {nuclei } \\
\text { in myofibres† }\end{array}$ & $\begin{array}{l}\% \mathrm{Y}^{+} \text {nuclei in } \\
\text { bone marrow } \neq\end{array}$ \\
\hline 1 & 17 & 7,000 & 9 (254) & 3 & 41 \\
\hline 2 & 21 & 10,000 & $3(276)$ & 7 & 75 \\
\hline 3 & 30 & 20,000 & $6(820)$ & 9 & 91 \\
\hline 4 & 30 & 13,000 & $5(800)$ & 6 & 30 \\
\hline 5 & 28 & 19,000 & ND & ND & 80 \\
\hline
\end{tabular}

*Dystrophin-positive fibres as a percentage of total number of fibres (total).

†Percentage of dystrophin-positive fibres for which a Y-chromosome-positive nucleus was detected in one given section (on average, 1 or 2 per section).

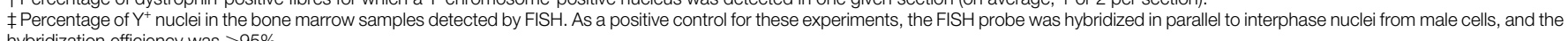
hybridization efficiency was $>95 \%$.

ND: not determined.

Hoechst dye ${ }^{10}$. In contrast, the MP myoblasts were unaffected by verapamil (Fig. 2b).

Characterization of muscle SP cells revealed several unique features that distinguished them from bone marrow SP and muscle MP cells. First, isolation of muscle SP cells required a concentration of $\mathrm{H} 0342$ dye that was 2.5 times greater than that used to purify bone marrow SP cells ${ }^{10}$. In addition, although both muscle and bone marrow SP cells were Sca- $1^{+} \operatorname{lin}^{-}$, as predicted for early progenitor cells, c-Kit and CD45, two surface markers expressed on bone marrow SP cells ${ }^{11}$, were not present on muscle SP cells (Fig. 2e, f). Similarly, over $90 \%$ of muscle SP cells were negative for CD43 (Fig. 2d), another marker detected on bone marrow SP cells. In contrast, muscle MP cells expressed several lineage markers $\left(\operatorname{lin}^{+}\right.$), such as CD11, Gr-1 and CD5 (Fig. 2f). The two muscle-cell populations were also different in appearance. In vitro culture experiments revealed that, after one week, nearly all MP cells adhered to the culture dish and were fully differentiated into myoblasts (Fig. 2h), with a few intervening fibroblasts as determined by desmin staining (data not shown). In contrast, most SP
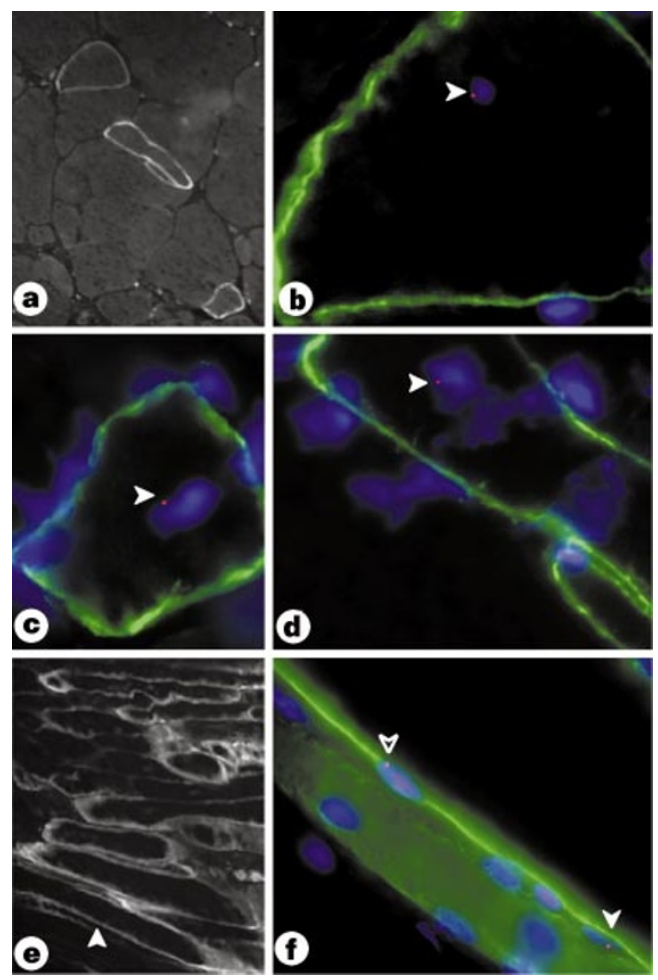

Figure 4 Dystrophin-positive fibres were detected in skeletal muscle tissue sections of animals 3 and 1. a, e, Low-magnification fields (original magnification (25x) showing the dystrophin-positive myofibres seen in $\mathbf{b}-\mathbf{d}$, respectively. a, Animal 3; e, animal 1. Solid arrowheads in $\mathbf{b}-\mathbf{d}$, $\mathbf{f}$ indicate at high magnification (100x) donor male nuclei fused to host dystrophin-positive myofibres. A donor nucleus appears to be juxtaposed to the sarcolemma of the myofibre, implying that it may be a satellite cell (f, open arrowhead). cells maintained a spherical shape and failed to settle on the plate (Fig. 2g). Only after 2 weeks in culture did muscle SP cells differentiate as a mixture of myoblasts and fibroblasts.

To evaluate the potential of muscle SP cells to contribute to muscle and/or haematopoietic compartments, we prepared muscle SP cells from normal C57BL/10 male mice and injected them into the tail veins of lethally irradiated female $m d x$ mice. Preliminary bone marrow transplantation experiments using muscle SP cells indicated that at least ten-fold more muscle SP cells than bone marrow SP cells were needed for reliable radioprotection (data not shown). Based on those studies, 7,000-20,000 male muscle SP cells were injected into five lethally irradiated $m d x$ females (Table 2 ). At day 17, one mouse injected with 7,000 muscle SP cells (Table 2, animal 1) appeared weak and was killed. The other animals were killed at 28-30 days, when all seemed in good health (Table 2, animals 2-5). Analysis of the bone marrow cells of the recipients by FISH indicated variable engraftment by donor cells, ranging from 30-91\% (Fig. 3a, d; Table 2). Metaphase spreads containing the Y chromosome were also detected by FISH (Fig. 3b, e), indicating that the introduced male muscle SP cells could divide in vivo. Giemsa staining of bone marrow samples of these animals revealed diverse types of haematopoietic cell (Fig. 3c, f). In addition to bone marrow, spleen tissue sections of animals 3 and 4 were immunostained with either anti-CD43 or anti-CD45 antibodies, two surface markers that are expressed by haematopoietic cells but not by muscle SP cells (Fig. 2f). Both antibodies revealed the presence of immunoreactive cells (Fig. 3g, h). Co-detection of donor nuclei by FISH showed that over $90 \%$ of the spleen cells, including those expressing CD43 or CD45, were positive for the Y chromosome and thus of donor origin (Fig. 3h). Collectively, these findings showed that muscle SP cells can reconstitute the haematopoietic compartment of lethally irradiated recipients, albeit less effectively than bone marrow SP cells. In fact, in competitive repopulation studies of lethally irradiated $m d x$ females injected with a mixture of 200 bone marrow SP cells derived from $m d x$ females and 6,000 muscle SP cells derived from normal males, less than $1 \%$ of the bone marrow nuclei were positive for the $\mathrm{Y}$ chromosome by FISH at 4 and 8 weeks (Fig. 3i).

To evaluate the ability of muscle SP cells to differentiate into muscle, bone marrow transplant recipients engrafted with muscle SP cells were analysed by immunohistochemistry combined with FISH (Table 2; Fig. 4). Analysis of 15-30 skeletal muscle tissue sections from each of four recipients revealed donor-derived dystrophin-positive myofibres, with on average one or two $\mathrm{Y}^{+}$nuclei fused to dystrophin-positive fibres in each section (Fig. 4). For animals injected with muscle SP cells, analysis of 18 photographed muscle tissue sections from three different animals revealed a pattern of nuclear localization similar to that seen in animals injected with bone marrow cells. Of a total of 28 donor male nuclei within dystrophin-positive myofibres, 12 nuclei were centrally located in the dystrophin-positive myofibres (Fig. 4b-d), 9 were peripherally located (Fig. 4f, solid arrowhead) and 7 were clearly fused to the myofibres but whether they were centrally or 
peripherally located was unclear. Furthermore, a few donor nuclei were detected juxtaposed to a myofibre (Fig. 4f, open arrowhead), at a position consistent with that of satellite cells ${ }^{13}$. Analysis of serial muscle tissue sections for the expression of dystrophin and laminin showed that donor male nuclei that were juxtaposed but not fused to dystrophin-positive myofibres were encompassed by laminin staining in the adjacent sections, implying that satellite cells arise after transplantation of muscle SP cells (data not shown). In contrast, analysis of more than 200 tissue sections from animals injected with either whole bone marrow or highly purified haematopoietic cells failed to reveal the presence of $\mathrm{Y}^{+}$nuclei at this position. Although these findings indicate that muscle-derived stem cells may differ from bone marrow derived stem cells in their capacity to give rise to satellite cells, more detailed studies of the precise anatomical position and molecular characteristics of these cells associated with donor-derived nuclei will be necessary to definitely address this issue.

Previous cell transplantation strategies aimed at the delivery of dystrophin have been quite successful ${ }^{4,14}$, but have required multiple, local intramuscular injections, as systemic delivery of cells to muscle through myoblast transplantation does not appear to occur $^{15}$. Similarly, the delivery of dystrophin to muscle by in vivo gene transfer with viral vectors has resulted in only local restoration of dystrophin ${ }^{16-19}$. The most important practical conclusion of our studies is that bone marrow or muscle SP cells appear to provide a means for the systemic, rather than local, repair of muscle, as a consequence of the delivery of the cells throughout the vascular system. Although, in general, the proportion of dystrophin-positive myofibres that resulted from stem cell transplantation was below the levels that would be likely to be needed to provide clinical benefit in patients with muscular dystrophy, it is possible that, in the future, the procedures for stem cell transplantation that we have employed could be optimized to provide levels of engraftment of muscle that would be clinically useful ${ }^{20,21}$.

Our studies also shed important new light on the biological properties of different stem cell populations. First, the experiments involving the transplantation of highly purified haematopoietic stem cells provide the first direct evidence that haematopoietic stem cells with the capacity for the complete reconstitution of lethally irradiated recipients have the potential to differentiate into muscle. Previous in vitro studies ${ }^{22-24}$ had indicated that mesenchymal stem cells of the bone marrow stroma might be the relevant source of the cells with muscle potential revealed by the earlier bone marrow transplantation studies of Ferrari et al. and Bittner et al. ${ }^{8,9}$. A second important biological finding from our studies is that, using purification methods similar to those used previously to isolate haematopoietic stem cells, a population of cells from muscle can be isolated with similar functional and phenotypic properties to those of haematopoietic stem cells isolated from bone marrow. These results raise the possibility that there may be some direct relationship between bone marrow derived stem cells and other tissue- or organ-specific stem cells. One possibility that needs to be explored further is that stem cells resident in specific tissues or organs originate from a common set of cells in the bone marrow, yet adopt tissue- or organ-specific characteristics upon seeding within a specific local environment. Alternatively, organ- and tissue-specific stem cell populations may arise solely as a consequence of the normal development of that specific tissue or organ, but in general share similar phenotypic and functional characteristics. In this regard, it is interesting that we have found that SP-like cells can be isolated from a number of other differentiated tissues and organs (unpublished results). Several studies have also shown that certain bone marrow derived cells have the potential to differentiate into other non-haematopoietic cells, such as endothelial cells ${ }^{25,26}$, and that some CNS-derived stem cell lines have the potential to differentiate into haematopoietic cell $\mathrm{s}^{27}$. Clearly, more studies to assess the origin and functional properties of different stem cell populations and their relationship to bone marrow derived stem cells are urgently needed.

\section{Methods}

\section{Mouse strains}

C57BL/10 mice and C57BL/10ScSn-Dmd $d^{m d x} / \mathrm{J}$ (X-linked muscular dystrophy) mice were obtained from the Jackson Laboratory.

\section{Purification of bone marrow and haematopoietic stem cells}

Bone marrow was extracted from the femurs and tibias of 6-8-week-old animals and red blood cells were removed with ammonium chloride solution (Sigma). To purify haematopoietic stem cells, bone marrow cells were resuspended at $10^{6}$ cells per $\mathrm{ml}$ and stained with $5 \mu \mathrm{g} \mathrm{ml}^{-1}$ Hoechst 33342 (Sigma) as described ${ }^{10}$. Cells were then magnetically preenriched for Sca-1-positive cells using the MACS (Miltenyi Biotec) and streptavidin microbeads. Before cell sorting, cells were resuspended in HBSS containing 2\% FCS and $2 \mu \mathrm{g} \mathrm{ml}^{-1}$ propidium iodide (PI). Flow cytometric analysis and cell sorting were performed on a dual-laser FACSVantage flow cytometer (Becton Dickinson). Both the Hoechst and propidium iodide dyes were excited at $350 \mathrm{~nm}$ and their fluorescence was measured at 450 and $600 \mathrm{~nm}$. The sorting gate for the haematopoietic stem cell population was established as described ${ }^{10}$.

\section{Isolation of muscle SP cells}

We isolated skeletal muscle myoblasts from 3-5-week-old donor male tissue as described $^{12}$. Before H0342 staining, red cells were lysed ${ }^{28}$. Primary myoblasts were resuspended at $10^{6}$ cells per ml and stained with $12.5 \mu \mathrm{g} \mathrm{ml}^{-1}$ of $\mathrm{H} 0342$ in PBS-0.5\%BSA for $90 \mathrm{~min}$ at $37^{\circ} \mathrm{C}$. In parallel, as a negative control for SP cells, we stained $10^{6}$ cells in the presence of $50 \mu \mathrm{M}$ verapamil and used them to set the gate for isolation of SP cells by FACS in the test sample ${ }^{10}$. Cells were washed once in cold PBS- $0.5 \% \mathrm{BSA}$, resuspended at $10^{8}$ cells per $\mathrm{ml}$ and incubated for $10 \mathrm{~min}$ on ice with $10 \mu \mathrm{g} \mathrm{ml}^{-1}$ of biotinylated anti-Sca-1 antibody (Pharmingen). For cell-lineage marker analysis, muscle SP and MP cells were stained as described ${ }^{10}$. Before FACS analysis and sorting, samples were enriched for Sca- $1^{+}$cells and stained with $2 \mu \mathrm{g} \mathrm{ml}^{-1} \mathrm{PI}^{10}$. Before being injected into animals, muscle SP cells were washed once in PBS- $0.5 \%$ BSA and resuspended in $200 \mu$ l of PBS- $0.5 \%$ BSA. For cell culture, muscle SP and MP myoblasts were maintained as described ${ }^{12}$.

\section{Bone marrow, haematopoietic or muscle stem cell transplantation}

Female $m d x$ recipients were lethally irradiated with 1200 rad given in two doses (600 rad each), $3 \mathrm{~h}$ apart. Bone marrow, haematopoietic or muscle stem cells were given intravenously into the tail vein. Mice were maintained on acidified water after transplantation. All animal care was in accordance with institutional guidelines.

\section{Tissue collection and FISH analysis}

Recipient animals were killed and skeletal muscle and spleen were snap-frozen in cold isopentane and stored at $-80^{\circ} \mathrm{C}$. The bone marrow was isolated from the hind leg bones Cells were washed in $1 \times$ PBS and filtered through a $70 \mu \mathrm{M}$ filter. For Giemsa staining, bone marrow cells were spread on a glass slide, fixed in methanol for $3 \mathrm{~min}$ and stained according to the manufacturer's instructions (Sigma). For FISH analysis of bone marrow nuclei, cells were treated with hypotonic solution and fixed in methanol and acetic acid before slide preparation as described ${ }^{29}$.

We prepared the Y-chromosome FISH probe (a gift from E. Snyder) by labelling $1 \mu \mathrm{g}$ of plasmid DNA with digoxigenin-11-dUTP as described ${ }^{29,30}$. FISH was standardized on whole nuclei isolated from a male murine muscle cell line and on male muscle tissue sections. The hybridization efficiency was $>90 \%$ on whole nuclei and $70-80 \%$ on tissue sections.

Immunohistochemistry and in situ hybridization were performed on the same tissue sections as described ${ }^{30}$. Slides were examined using a Zeiss Axiophot microscope and images were collected using a CCD camera (Photometrics) as described ${ }^{30}$

Received 10 May; accepted 19 July 1999.

1. Mulligan, R. C. The basic science of gene therapy. Science 260, 926-932 (1993).

2. Sicinski, P. et al. The molecular basis of muscular dystrophy in the mdx mouse: a point mutation. Science 244, 1578-1580 (1989).

3. Hall, Z. W. \& Ralston, E. A. Nuclear domains in muscle cells. Cell 59, 771-772 (1989).

4. Karpati, G. et al. Dystrophin is expressed in mdx skeletal muscle fibers after normal myoblast implantation. Am. J. Pathol. 135, 27-32 (1989).

5. Pavlath, G. K., Rich, K., Webster, S. G. \& Blau, H. M. Localization of muscle gene products in nuclear domains. Nature 337, 570-573 (1989).

6. Gussoni, E., Blau, H. M. \& Kunkel, L. M. The fate of individual myoblasts after transplantation into muscles of DMD patients. Nature Med. 3, 970-977 (1997).

7. Hoffman, E. P., Morgan, J. E., Watkins, S. C. \& Partridge, T. A. Somatic reversion/suppression of the mouse $\mathrm{mdx}$ phenotype in vivo. J. Neurol. Sci. 99, 9-25 (1990).

8. Ferrari, G. et al. Muscle regeneration by bone marrow-derived myogenic progenitors. Science 279, 1528-1530 (1998).

9. Bittner, R. E. et al. Recruitment of bone marrow-derived cells by skeletal and cardiac muscle in adult dystrophic mdx mice. Anat. Embryol. (Berl.) 199, 391-396 (1999).

10. Goodell, M. A., Brose, K., Paradis, G., Conner, A. S. \& Mulligan, R. C. Isolation and functional properties of murine hematopoietic stem cells that are replicating in vivo. J. Exp. Med. 183, 1797-1806 (1996) 
11. Goodell, M. A. et al. Dye efflux studies suggest that hematopoietic stem cells expressing low or undetectable levels of CD34 antigen exist in multiple species. Nature Med. 3, 1337-1345 (1997).

12. Rando, T. A. \& Blau, H. M. Primary mouse myoblast purification, characterization, and transplantation for cell-mediated gene therapy. J. Cell Biol. 125, 1275-1287 (1994).

13. Mauro, A. Satellite cells of skeletal muscle. J. Biophys. Biochem. Cytol. 9, 493-495 (1961).

14. Partridge, T. A., Morgan, J. E., Coulton, G. R., Hoffman, E. P. \& Kunkel, L. M. Conversion of mdx myofibers from dystrophin negative to positive by injection of normal myoblasts. Nature 337, 176 179 (1989)

15. Partridge, T. A. Invited review: myoblast transfer: a possible therapy for inherited myopathies? Muscle Nerve 14, 197-212 (1991)

16. Acsadi, G. et al. Human dystrophin expression in mdx mice after intramuscular injections of DNA constructs. Nature 352, 815-818 (1991).

17. Acsadi, G. et al. Human dystrophin expression in $\mathrm{mdx}$ mice after intramuscular injections of DNA constructs. Nature 352, 815-818 (1991).

18. Ragot, T. et al. Efficient adenovirus-mediated transfer of a human minidystrophin gene to skeletal muscle of mdx mice. Nature 361, 647-650 (1993).

19. Kochanek, S. et al. A new adenoviral vector: replacement of all viral coding sequences with $28 \mathrm{~kb}$ of DNA independently expressing both full-length dystrophin and b-galactosidase. Proc. Natl Acad. Sci. USA 93, 5731-5736 (1996)

20. Rafael, J. A. et al. Prevention of dystrophic pathology in mdx mice by a truncated dystrophin isoform Hum. Mol. Genet. 3, 1725-1733 (1994).

21. Phelps, S. F. et al. Expression of full-length and truncated dystrophin mini-genes in transgenic $\mathrm{mdx}$ mice. Hum. Mol. Genet. 4, 1251-1258 (1995).

22. Pereira, R. F. et al. Cultured adherent cells from marrow can serve as long-lasting precursor cells for bone, cartilage, and lung in irradiated mice. Proc. Natl Acad. Sci. USA 92, 4857-4861 (1995).

23. Saito, T. et al. Myogenic expression of mesenchymal stem cells within myotubes of mdx mice in vitro and in vivo. Tissue Eng. 1, 327-343 (1995).

24. Prockop, D. J. Marrow stromal cells as stem cells for nonhematopoietic tissues. Science 276, 71-74 (1997).

25. Asahara, T. et al. Isolation of putative progenitor endothelial cells for angiogenesis. Science $\mathbf{2 7 5}, 964$ 967 (1997)

26. Shi, Q. et al. Evidence for circulating bone marrow-derived endothelial cells. Blood 92, 362-367 (1998).

27. Bjornson, C. R., Rietze, R. L., Reynolds, B. A., Magli, M. C. \& Vescovi, A. L. Turning brain into blood: a hematopoietic fate adopted by adult neural stem cells in vivo. Science 283, 534-537 (1999).

28. Baroffio, A., Bochaton-Piallat, M.-L., Gabbiani, G. \& Bader, C. R. Heterogeneity in the progeny of single human muscle satellite cells. Differentiation 59, 259-268 (1995).

29. Lichter, P. et al. Rapid detection of human chromosome 21 aberrations by in situ hybridization. Proc Natl Acad. Sci. USA 85, 9664-9668 (1988).

30. Gussoni, E. et al. A method to codetect introduced genes and their products in gene therapy protocols Nature Biotech. 14, 1012-1016 (1996).

\section{Acknowledgements}

We thank E. Snyder for the mouse Y-chromosome probe. This work was supported by the Muscular Dystrophy Association (L.M.K.), the Bernard and Alva Gimbel Foundation and Family (L.M.K.), the Howard Hughes Medical Institute (L.M.K., R.C.M.) and the NIH (R.C.M.). L.M.K. and R.C.M. are Investigators of the Howard Hughes Medical Institute.

Correspondence and requests for materials should be addressed to R.C.M. (e-mail: mulligan@rascal.med.harvard.edu) or L.M.K. (e-mail: kunkel@rascal.med.harvard.edu).

\section{Evidencethatafree-running oscillator} drives $\mathrm{G1}$ events in the budding yeast cell cycle

\section{Steven B. Haase \& Steven I. Reed}

Department of Molecular Biology, The Scripps Research Institute, 10550 North Torrey Pines Road, La Jolla, California 94303, USA

In yeast and somatic cells, mechanisms ensure cell-cycle events are initiated only when preceding events have been completed ${ }^{1}$. In contrast, interruption of specific cell-cycle processes in early embryonic cells of many organisms does not affect the timing of subsequent events ${ }^{2}$, indicating that cell-cycle events are triggered by a free-running cell-cycle oscillator. Here we present evidence for an independent cell-cycle oscillator in the budding yeast Saccharomyces cerevisiae. We observed periodic activation of events normally restricted to the G1 phase of the cell cycle, in cells lacking mitotic cyclin-dependent kinase activities that are essential for cell-cycle progression. As in embryonic cells, G1 events cycled on schedule, in the absence of $S$ phase or mitosis, with a period similar to the cell-cycle time of wild-type cells. Oscillations of similar periodicity were observed in cells responding to mating pheromone in the absence of G1 cyclin (Cln)- and mitotic cyclin $(\mathrm{Clb})$-associated kinase activity, indicating that the oscillator may function independently of cyclin-dependent kinase dynamics. We also show that $\mathrm{Clb}$-associated kinase activity is essential for ensuring dependencies by preventing the initiation of new G1 events when cell-cycle progression is delayed.

In wild-type budding yeast, completion of cell-cycle events in one cell-cycle phase is essential for the transition to the next phase ${ }^{1}$, although mutants have been identified that can initiate synchronous, periodic rounds of budding in the absence of DNA replication and mitosis ${ }^{3}$. Strains bearing temperature-sensitive mutations in genes involved in protein degradation, $c d c 4, c d c 34$ or $c d c 53$, cannot enter $S$ phase or mitosis but do initiate synchronous rounds of budding at the restrictive temperature ${ }^{4}$. The molecular basis for the inability of these mutants to replicate DNA or complete mitosis is related to the stabilization of the $\mathrm{Clb} / \mathrm{Cdc} 28$-specific inhibitor, Siclp, and the consequent loss of Clb-kinase activity ${ }^{5}$. That $c d c 4$, $c d c 34$ and $c d c 53$ cells produce multiple buds indicates that the initiation of G1 events may be uncoupled from the completion of S phase or mitosis by the loss of Clb-associated kinase activity.

To investigate this idea, we analysed events normally restricted to G1 in synchronous populations of cells bearing the temperaturesensitive mutation $c d c 4-3$, or cells disrupted for all six B-type cyclin genes. Synchronous populations of G1 cells were collected by centrifugal elutriation, and then shifted to the restrictive temperature $\left(36^{\circ} \mathrm{C}\right)$. Budding and transcript levels were analysed at 10 -min intervals. Synchronous oscillations of CLN2 transcript levels were reproducibly observed with periods coinciding with the budding cycles (Fig. 1d-f, g-i). The cycling of G1 events indicates the existence of an oscillator that cycles independently of B-type cyclin activity and the completion of $\mathrm{S}$ phase or mitosis. The period of budding and transcription cycles in cells lacking B-type cyclin activity is very similar to the period observed in normally dividing wild-type cells (Fig. 1a-c), indicating that G1 events in normally dividing cells may be entrained to the same independent oscillator.

Activation of $\mathrm{Cln} / \mathrm{Cdc} 28$ kinase is a critical G1 event that is required for the initiation of budding and the transition from $\mathrm{G} 1$ to $S$ phase ${ }^{6}$. Therefore, we investigated whether the oscillations in CLN2 transcript levels in cells lacking $\mathrm{Clb}$ activity led to functional oscillations in $\mathrm{Cln} 2$-associated kinase. Indeed, $\mathrm{Cln} 2$-associated kinase did oscillate synchronously with the appearance of new buds in $c d c 4-3$ cells (Fig. 1j, k). However, it is likely that the oscillation of $\mathrm{Cln} 2$-associated kinase activity is not essential for driving budding cycles, as constitutive expression of $\mathrm{Cln} 2$ from the GAL1 promoter did not prevent rebudding in $c d c 4-3$ cells (data not shown). Other events essential for rebudding cycles may be entrained to the oscillator independently of Cln2-associated kinase activity (see below).

As Clns can auto-activate their own transcription ${ }^{7,8}$ and also appear to stimulate their own proteolysis ${ }^{9,10}$, they could conceivably define an oscillator that drives G1 events in the absence of cell-cycle progression. Our finding that $c d c 4-3 c d c 28-4$ double mutant cells do not exhibit budding or G1-specific transcription cycles indicates that $\mathrm{Cln} / \mathrm{Cdc} 28$ kinase activity may be essential for these events (data not shown). However, our experiments do not distinguish whether Clns are components of an oscillator or are simply entrained to a Cln-independent oscillator, as the outputs we measured (budding and transcription) are themselves dependent on $\mathrm{Cln} / \mathrm{Cdc} 28$-kinase activity.

Previous observations indicate that measurable oscillations may occur independent of $\mathrm{Cln} / \mathrm{Clb}$-associated kinase activity. In response to mating pheromone, budding yeast adopt a unique morphology, termed 'shmoo', by polarizing growth to form a 